\title{
Novel Drug Delivery Strategies: New Concepts
}

\section{Patil JS*}

VT's Shivajirao S Jondhle College of Pharmacy, Asangaon-421 601, Thane, Mumbai, Maharashtra, India

\section{Introduction}

The biopharmaceutical performance of an existing drug molecule can be significantly improved through its evolution from a conventional form to a novel delivery system. Apart from biopharmaceutical performances, the safety, efficacy and patient compliance are also improved for a drug molecule. Present day drug delivery companies are emphasizing prominently on development of multiple platform technologies for getting competitive merits, expand patent span, and enhance market share of their products. The quantum of novel drug delivery products has significantly increased in the past few years, and this growth is expected to continue in the near future. Today large numbers of companies are busy developing protein and peptide based drug molecules due to advancement in the field of genomics which in turn accelerated research of biopharmaceuticals. Due to the unique nature of biopharmaceuticals it is difficult to deliver them by conventional routes and this presents challenges to the drug delivery scientists. Therefore, present research is focusing on the delivery of these complex molecules through different routes including oral, nasal, pulmonary, vaginal, rectal, buccal, colon specific, etc. [1].

\section{Merits of novel drug delivery system}

Due to increasing cost of successful drug discovery, the present pharmaceutical industry is under the stress of downward pressure on prices of pharmaceutical products. The costs as well as time for development of a new chemical entity are much higher than those required to develop a new drug delivery system. A novel drug delivery system gives new life to a drug molecule, thereby increases its market value and competitiveness and extending patent life. In past couple of years, there has been a significant increase in novel drug delivery approvals and this is expected to continue at an impressive rate in the near future [2].

\section{Current status of drug delivery technologies}

Designing a novel drug delivery system by incorporating an existing medicine into a new system can significantly improve its performance in terms of efficacy, safety, and improved patient compliance. The need for design of novel drug delivery devices with the aim to enhances their efficiency and minimize the side effects has encouraged pharmaceutical companies to engage in the development of new drug delivery systems. Present day pharmaceutical companies are engaged in the development of multiple platform technologies for controlled release, delivery of macro molecules, particulate drug delivery, nanoproducts, liposomes-neosomes, rapid dispersing dosage forms, and delivery of drugs through intranasal, pulmonary, transdermal, vaginal, rectal, colon, intra brain, and trans mucosal routes [3].

\section{Present scenario}

Through novel ways drugs can be delivered to a patient by different delivery systems. Most of the drugs are delivering through these delivery systems. The advances in the human genome and biotechnology enable most of the companies to develop a large number of macromolecules. Now, the protein- and peptide-based drugs constitute more than half of the new drugs available in the market, and more than $80 \%$ of these protein drugs are antibodies. The biopharmaceuticals such as proteins, peptides, carbohydrates, oligo-nucleotides, and nucleic acids in the form of DNA are macromolecule in nature; degrade rapidly in the blood stream and present drug delivery challenges. Moreover, these macromolecules experience difficulty in crossing cell membranes and generally cannot be delivered orally. Many biotech companies are involved in drug delivery task; hence, gene therapy is also likely to be one of the most exciting growth sectors. Currently, several genetically engineered cells are in Phase III clinical trials.

\section{Conclusion}

There is a continuous growth in the market of drug delivery systems and will continue to grow at an impressive rate in future also. The advanced drug delivery technologies today enable us to formulate the novel drug delivery devices by incorporating the drug molecules into new delivery systems, thus providing numerous therapeutic and commercial advantages. It is evident from the increased number of novel products in the market and the number of patents granted in the recent past that a large number of companies are involved in the development of new drug delivery systems. The drugs which come into market in future will be more challenging and may present difficulties in the development of delivery systems, and pharmaceutical scientists will have to be ready for a difficult task ahead.

\section{References}

1. S Engel (1999) Delivering Results. $R$ and $D$ Directions 5: 48-64.

2. S Engel (1998) Smashing the Barriers. $R$ and $D$ Directions 4: 44-67.

3. RK Verma, S Garg (2001) Current Status of Drug Delivery Technologies and Future Directions. Pharm Technol On-Line 25: 1-14.

*Corresponding author: Patil JS, VT's Shivajirao S Jondhle College of Pharmacy, Asangaon-421 601, Thane, Mumbai, Maharashtra, India, Tel: 09594962017; E-mail: pharmajspati@gmail.com

Received August 21, 2015; Accepted August 26, 2015; Published August 28 2015

Citation: Patil JS (2015) Novel Drug Delivery Strategies: New Concepts. Adv Pharmacoepidemiol Drug Saf 4: e134. doi:10.4172/2167-1052.1000e134

Copyright: @ 2015 Patil JS. This is an open-access article distributed under the terms of the Creative Commons Attribution License, which permits unrestricted use, distribution, and reproduction in any medium, provided the original author and source are credited. 